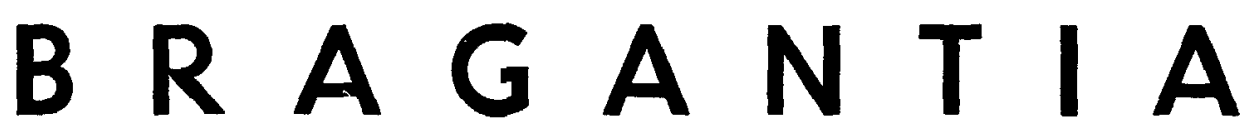

Revista Científica do Instituto Agronômico do Estado de São Paulo

Vol. 36

Campinas, abril de 1977

N. 9

\title{
APLICAÇÃO PARCELADA DE CALCÁRIO NA CULTURA DO ALGODOEIRO $\left({ }^{1}\right)$
}

\author{
Carlos A. M. Ferraz $\left({ }^{2}\right)$, Francisco S. O. Rodrigues Filho $\left({ }^{2}\right)$, Edivaldo Cia $\left({ }^{2}\right)$, \\ Nélson Machado da Silva $\left({ }^{2}\right)$, Seção de Algodão, e Nélson P. Sabino $\left({ }^{2}\right)$, \\ Seçāo de Tecnologia de Fibras, Instituto Agronômico
}

\section{SINOPSE}

Ensaios de campo foram conduzidos por um periodo de seis anos agrícolas, de 1967/68 a 1972/73, em latossolo roxo, no Centro Experimental de Campinas para estudar os efeitos de diferentes modos de aplicação de calcário e sel efeito residual na cultura do algodoeiro.

Os tratamentos comparados foram os seguintes: sem aplicação de calcário; dase total de calcário aplicada no primeiro ano: metade da dose aplicada no primeiro ano e metade no segundo; um terço da dose aplicada no primeiro ano, um terço no segundo e um terço no terceiro; metade da dose aplicada no primeiro ano e metade no terceiro ano. Todos os tratamentos em presença de uma adubação mineral NPK. A dose total de calcário foi de 4,5 t/ha.

A avaliação do efeito da aplicação de calcário foi feita pela produção de algodão em caroço, pelas características de produção (peso de 1 capulho, peso de 100 sementes é porcentagem de fibra) e pelas características tecnológicas de fibra (comprimento, uniformidade, Pressley e Micronaire).

Os resultadios revelam que houve efeito significativo devido à aplicação de calcário sobre a produção do algodoeiro, nâo tendo sido, no entanto, detectado efeito entre os diferentes modos de parcelamentos estudadas. Os aumentos de produçāo variaram de 18 a $25 \%$, em relação à testemunha sem calcário.

O efeito residual do calcário foi significativo apenas para as aplicacoóes feitas metade da dose no $10^{\circ}$ ano e metade no $20^{\circ}$ e um terço da dose em cada ano, em relação à testemunha sem calcário; os demais tratamentos não diferiram dessa testemunha.

Não foi verificado efeito da aplicaçāo de calcário, nem efeito residual, sobre as características de produçāo e tecnológicas da fibra.

(1) Trabalho apresentado na XXVIII Reunião Anual da S.B.P.C. realizada em Brasília, DF, de 7 a 14 de julho de 1976. Recebido para publicação em 20 de agosto de 1976.

(2) Com bolsa de suplementação do C.N.Pq. 


\section{1 - INTRODUÇÃO}

A importância da acidez na fertilidade do solo é um problema já conhecido há bastante tempo, estando incluído como um dos fatores de grande influência para o sucesso da exploração agrícola $(3,5,6,13,17)$.

Os principais efeitos da acidez do solo dizem respeito às limitações nas disponibilidades dos nutrientes, como do fósforo, à redução do processo da nitrificação, à elevação nos teores de alumínio tóxico e ao decréscimo das bases trocáveis, principalmente cálcio e magnésio. Esses efeitos refletem desfavoravelmente sobre o crescimento das plantas e a produção das culturas $(\mathbf{2}, 11,14,18)$.

$\mathrm{O}$ algodoeiro não tolera solos ácidos, onde o $\mathrm{pH}$ esteja abaixo de 5,2 , devendo ser realizada a prática da calagem, de preferência empregando calcário dolomítico, associada à adubação mineral N $\mathrm{P}$ K para que seja alcançado sucesso na sua exploração (8).

Com o propósito de atenuar os inconvenientes causados pela acidez do solo, vários trabalhos foram realizados com o objetivo de elevar o índice de $\mathrm{pH}$, de fornecer cálcio e magnésio às plantas, bem como de verificar a eficiência de diferentes materiais que possam ser empregados como corretivos $(4,7,10,17,19)$. Entretanto, com respeito aos modos de aplicação de calcário foram realizados poucos trabalhos $(\mathbf{1 , 1 0 , 1 2 )}$.

Segundo Buckman \& Brady (2), Fuzatto (8), Wutke (18), a aplicação parcelada de calcário permite um melhor emprego do produto, evitando suas possíveis perdas no solo e dá tempo suficiente para que se proces- sem as transformações necessárias de correção da acidez do solo.

O presente trabalho teve por finalidade estudar o efeito da aplicação parcelada.de calcário dolomítico na cultura do algodoeiro (Gossypium hirsutum L.) durante os anos agrícolas de 1967/68 a 1972/73.

\section{2 - MATERIAL E MÉTODOS}

O estudo foi conduzido em caráter permanente, durante os anos agrícolas de 1967/68 a 1972/73, no Centro Experimental de Campinas. $O$ solo onde foi instalado o ensaio era ácido, de baixa fertilidade, classificado como latossolo roxo, série chapadão, segundo levantamento realizadơ pela Seção de Pedologia do IAC $\left(\mathrm{pH}=4,90, \mathrm{PO}_{4}{ }^{3-}=0,05\right.$, $\mathrm{K}^{+}=0,13, \mathrm{Ca}^{2+} \mathrm{Mg}^{2+}=1,43$ e $\mathrm{Al}^{3+}=0,70$ ).

Para o estudo foram utilizados cinco tratamentos, com seis repetições a saber:

1. $\mathbf{T}=$ Testemunha sem aplicação de calcário

2. $\mathrm{C}=$ Dose total de calcário

3. $1 / 2 \mathrm{C}$ no primeiro ano

$1 / 2 \mathrm{C}$ no segundo ano

4. 1/3 C no primeiro ano

$1 / 3 \mathrm{C}$ no segundo ano

$1 / 3 \mathrm{C}$ no terceiro ano

5. $1 / 2 \mathrm{C}$ no prìmeiro ano

$1 / 2$ C no terceiro ano

A dose de calcáriơ foi calculada em $4.500 \mathrm{~kg} / \mathrm{ha}$, baseada em estudos de Catani \& Gallo (4), e aplicada, de acordo com os tratamentos, nos anos de $1967 / 68$ a $1969 / 70$, sempre com bastante antecedência do plantio, na superfície do solo e incorporada com 
auxílio de grade. Nos anos agrícolas de 1970/71 a 1972/73 não foi feita a aplicação de calcário, assim permitindo estudar o efeito residual da calagem feita nos anos anteriores.

A adubação mineral básica foi calculada de acordo com a resposta esperada da planta e conforme indicações técnicas da Seção de Algodão, constituindo-se de $10-90-$ $80 \mathrm{~kg} / \mathrm{ha}$ de $\mathrm{N}, \mathrm{P}_{2} \mathrm{O}_{\overline{5}}$ e $\mathrm{K}_{2} 0$, respectivamente, aplicada no sulco de plantio em posição lateral e abaixo do nível das sementes. Foi realizada uma adubação nitrogenada em cobertura, na base de $30 \mathrm{~kg} / \mathrm{N} / \mathrm{ha}$, ao lado das linhas de plantio, logo após o desbaste das plantas.

As parcelas experimentais foram constituídas por seis linhas de $5 \mathrm{~m}$ de comprimento, sendo consideradas úteis para o estudo apenas as duas linhas centrais. $\mathrm{O}$ espaçamento entre linhas foi de $0,80 \mathrm{~m}$. Foram deixadas 25 plantas por linha, por ocasião do desbaste.

Quando $70 \%$ dos frutos +estavam completamente abertos e bem formados foi realizada a $1 .^{\text {a }}$ colheita, ocasião em que foram retiradas amostras de 20 capulhos da parte média das plantas, nas linhas centrais. Estas amostras serviram para estudos das características de produção (peso de 1 capulho, peso de cem sementes e de porcentagem de fibra) e de fibra (comprimento e uniformidade de fibra, Micronaire e Pressley) (16). Trinta dias após a primeira colheita foi realizada uma segunda e somada àquela, sendo os resultados transformados em $\mathrm{kg} / \mathrm{ha}$ de algodão em caroço. Para comparação entre as médias de tratamentos foi utilizado o teste de Tukey ao nível de $5 \%$ de probabilidade.

\section{3 - RESULTADOS E DISCUSSÃO}

Os resultados de produção de algodão em caroço obtidos durante os anos agrícolas de 1967/68 a $1972 / 73$, são mostrados nos quadros $1 \mathrm{e} 2$.

Pode-se verificar que houve grande variação nos resultados de produção do algodoeiro no decorrer dos anos, variação esta não influenciada pela aplicação de calcário, mas sim pelas condições ambientes ocorridas naqueles anos. Relacionando os resultados anuais do experimento e as médias de produção da lavoura paulista, naqueles anos, verifica-se uma concordância nơs resultados obtidos.

Nos anos agrícolas de 1967/68 a 1969/70 foi estudado o efeito da aplicação parcelada de calcário, e nos anos de 1970/71 a 1972/73, o seu efeito residual.

Os resultados na produção de algodão do efeito da aplicação parcelada de calcário nos anos de 1967/68 a 1969/70 são mostrados no quadro 1 .

Pode-se observar, pelo quadro 1 , que na média dos três anos agrícolas houve efeito significativo entre tratamentos, sendo que todos os tratamentos que receberam calcáriơ foram superiores ao tratamento em que aquele corretivo foi omitido; os aumentos de produção de algodão variaram de 18 a $25 \%$. Não houve, entretanto, diferença significativa entre os modos de aplicação de calcário estudados, indicando que tanto faz aplicar o calcário de uma só vez como parcelá-lo em duas - ou três vezes; os parcelamentos da dose total em duas vezes proporcionaram os maiores aumentơs de produção de algodão, ex- 
QUADRO 1. - Resultados médios de produção de algodão em caroço, em $\mathrm{kg} / \mathrm{ha}$, obtidos no experimento de parcelamento da aplicação de calcário referentes à aplicação de cálcário, durante três anos agrícolas, em Campinas

\begin{tabular}{|c|c|c|c|c|c|}
\hline Tratamento & $1967 / 68$ & $1968 / 69$ & $1969 / 70$ & \multicolumn{2}{|c|}{ Média } \\
\hline & & & & & Rel. (') \\
\hline 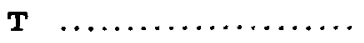 & 2.206 & 4.521 & 1.535 & $2.754 b^{(2)}$ & 100 \\
\hline $\mathbf{c} \quad \ldots \ldots \ldots \ldots \ldots \ldots \ldots$ & 2.885 & 4.979 & 2.038 & $3.301 \mathrm{a}$ & 120 \\
\hline $1 / 2$ C $\left(10^{\circ}\right.$ e 2 , ano $) \ldots$ & 2.496 & 5.375 & 2.277 & $3.383 \mathrm{a}$ & 123 \\
\hline $1 / 3 c \ldots \ldots \ldots \ldots \ldots \ldots$ & 2.398 & 5.104 & 2.288 & $3.263 \mathrm{a}$ & 118 \\
\hline $1 / 2 \mathrm{C}\left(1 .^{\circ}\right.$ e $3 .^{\circ}$ ano $) \ldots$ & 2.690 & 5.313 & 2.300 & $3.434 \mathrm{a}$ & 125 \\
\hline
\end{tabular}

(1) Produção relativa

(2) Médias seguidas de letras iguais não diferem estatisticamente entre si (Tukey 5\%).

QUADRO 2. - Resultados médios de produção de algodāo em caroço, em $\mathrm{kg} / \mathrm{ha}$, obtidos no experimento de parcelamento da aplicação de calcário, referentes aos efeitos residuais de calcário, durante três anos agricolas, em Campinas

\begin{tabular}{|c|c|c|c|c|c|}
\hline Tratamento & $1970 / 71$ & $1971 / 72$ & $1972 / 73$ & \multicolumn{2}{|c|}{ Média } \\
\hline & & & & & Rel. (1) \\
\hline 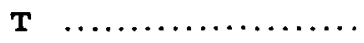 & 2.019 & 1.427 & 3.608 & $2.351 b\left({ }^{2}\right)$ & 100 \\
\hline $\mathbf{C} \quad \ldots \ldots \ldots \ldots \ldots \ldots \ldots \ldots$ & 2.217 & 1.515 & 4.008 & $2.580 \mathrm{ab}$ & 109 \\
\hline $1 / 2 \mathrm{C}\left(10^{\circ}\right.$ e 2 . ano $) \ldots$ & 2.377 & 1.758 & 4.575 & $2.903 \mathrm{a}$ & 123 \\
\hline $1 / 3 \mathrm{C} \ldots \ldots \ldots \ldots \ldots \ldots$ & 2.256 & 1.775 & 4.275 & $2.768 \mathrm{a}$ & 118 \\
\hline $1 / 2 \mathrm{C}\left(1 .^{\circ}\right.$ e $3 .^{\circ}$ ano $) \ldots$ & 2.188 & 1.723 & 4.198 & $2.703 \mathrm{ab}$ & 115 \\
\hline
\end{tabular}

(1) Produção relativa

(2) Médias seguidas de letras iguais não diferem estatisticamente entre si (Tukey $5 \%$ ).

ceção feita no $1 .^{\circ}$ ano de aplicação do corretivo $(67 / 68)$ em que a aplicação da dose total foi sùperior a todos os outros modos de aplicação.

Os resultados obtidos não confirmam os dados de Mikkelsen e colab. (12), que obtiveram aumento de $80 \%$ na produção de algơdão com o parcelamento da dose total de calcário, em relação ao tratamento em que o corretivo foi aplicado de uma só vez. Amaral e colab. (1), em estudos de parcelamento de aplicação de calcário na cultura de milho, verificaram que os melhores aumentos de produção do cereal foram conseguidos quando a aplicação do calcário foi parcelada em três vezes, embơra não tenham encontrado diferenças estatísticas entre as várias formas de aplicação do corretivo.

Os resultados do efeito residual do calcário sobre a produção do algodoeiro, durante os anos agrícolas de 1970/71 a 1972/73, encontram-se no quadro 2 . 
Por esses resultados observa-se que, na média dos três anos agrícolas, houve efeito residual significativo do calcáriơ para as aplicações da metade da dose total feita no $1 .^{\circ}$ ano e metade no $2 .^{\circ}$, e para as aplicações de um terço da dose total em cada ano, sendo que os aumentos de produção, em relação ao tratamento testemunha, foram de 23 e $18 \%$ respectivamente; embora não tenham sido significativamente diferentes do tratamento em que foi aplicada a dose total de uma só vez, os tratamentos com doses parceladas tiveram produções mais elevadas (6 e 14\%). Pode-se dizer que os resultados obtidos estão em acordo com os dados encontrados na literatura, de que o parcelamento na aplicação de calcário proporciona melhores condições de desenvolvimento e produção das culturas $(13,17)$ e com os resultados obiidos por Ferraz (6), que verificou efeito residual da aplicação de calcário sobre a produção do algodoeiro.

Novos estudos deverão ser conduzidos, sendo esses acompanhados das análises de terra, principalmente quanto aos teores de cálcio e magnésio trocáveis, alumínio tóxico e $\mathrm{pH}$, elementos da fertilidade do solo que também são influenciados pela aplicação de calcário $(2,13,18)$.

Os resultados de peso de capu1ho, peso de cem sementes e de porcentagem de fibra, chamados de características de produção, não foram influenciados estatisticamente pela aplicação de calcário.

De um modo geral, os estudos de fertilidade relacionados com as características de produção são em sua maioria relativos aos efeitos dos nutrientes nitrogênio, fósforo e potássio, não tendo sido encontrada lite. ratura referente aos efeitos da aplicação de calcário sobre as referidas características.

Também as características tecnológicas da fibra, (comprimento, unifoumidade, micronaire e Pressley), não foram influenciados pela aplicação di calcário, estando os resultados de acordo com aqueles encontrados por Sabino (15). Apenas os dados de comprimento da fibra mostraram uma tendência de aumento devido ao efeito residual do corretivo, em relação ao tratamento onde aquele material não foi aplicado, porém, sem significância estatística.

\section{4 - CONCLUSÕES}

a) $\mathrm{O}$ efeito da aplicação de calcário sobre a produção do algodoeiro foi significativo, com aumentos variando de 18 a $25 \%$, em relação ao tratamento onde o corretivo não foi aplicado.

b) Não se observou efeito significativo entre os diferentes modos de aplicação de calcário.

c) $\mathrm{O}$ efeito residual do calcário foi significativo para os parcelamentos metade da dose total do $1 .^{\circ}$ ano e metade no $2 .^{\circ}$ ano e um terço da dose total em cada ano, cujos aumentos foram de 23 e $18 \%$, respectivamente.

d) Não se verificou efeito significativo da aplicação de càlcário nas características de produção (peso de 1 capulho, peso de 100 sementes e porcentagem de fibra) e nas qualidades tecnológicas da fibra (comprimento, uniformidade, micronaire e Pressley). 


\section{PARCELLED APPLICATION OF LIME FOR COTTON}

\section{SUMMARY}

A study was carried out during the period of $1967 / 68$ to $1972 / 73$, in latosolic soil, "Serie Chapadão", in the "Centro Experimental de Campinas" - State of São Faulo, about the effects of parcelled application of lime on cotton culture (Gossypium hirsutum L.).

Lime was applied in 1967, 1968, and 1969, being studied in 1970, 1971, and 1972 its residual effects.

The results showed significant effects of the application of lime on cotton production, without significant differences among the types of application.

The residual effects also showed significant influence on cotton production. the fiber.

Lime had no significant effects on other economical characters of the plant and

\section{LITERATURA CITADA}

1. AMARAL, A. Z.; VERDADE, F. C.; SCHMIDT, N. C.; WUTKE, A. C. P.; \& IGUE, K. Parcelamento e intervalo da aplicação de calcário. Bragantia 24:83-96, 1965.

2. BUCKMAN, O. \& BRADY, N. C. Natureza e propriedade do solo. $2 .^{\text {a }}$ ed. Rio de Janeiro, Freitas Bastos, 1968. 594 p.

3. Camargo, T. de \& MEllo, P. C. de. O papel do cálcio na conservação do poder absorvente do solo. Campinas, Instituto Agronômico, 1934. (Boletim Técnico n. ${ }^{\circ}$ 13)

4. CATANI, R. A. \& GALLo, J. R. Avaliaçăo da exigência em calcário dos solos do Estado de São Paulo, mediante correlação entre o pH e a porcentagem de saturação em bases. Rev. Agríc., Piracicaba 30:49-60, 1965.

5. CESAR, H. P. Importância do cálcio na agricultura. Rev. Agríc. Piracicaba $11: 162-164,1936$.

6. FERRAZ, C. A. M. Efeitos do calcário, fósforo e potássio na produtividade do algodoeiro (Gossypium hirsutum, L.) em latossolo roxo. Botucatu, Faculdade de Ciências Médicas e Biológicas, 1974. $70 \mathrm{p}$. (Tese de doutoramento)

7. FRETTAS, L. M. M.; PRATT, P. F. \& VETTORI, L. Testes rápidos para estimar as necessidades em calcário em alguns solos de São Paulo. Pesq. agroc. bras. 3:159-164, 1968.

8. FUZATTO, M. G. Adubação mineral. In Instituto Brasileiro da Potassa, ed. Cultura e adubação do algodoeiro. São Paulo, 1965. 567 p.

9. - SILVA, N. M. \& CORREA, F. A. O efeito das fertilizaçōes nas caracteristicas do produto do algodoeiro. In: Reunião Anual da S. B. P. C., 7. ${ }^{2}$, Belo Horizonte, Minas Gerais, 1965. (Resumos, p. 198-199)

10. GaRGanTiNI, H.; GOMES, A. G. \& BLANCO, A. G. Modos de aplicação ao solo de materiais corretivos da acidez. Bragantia 31:403-410, 1965.

11. Malavolta, E. Manual de Química Agrícola. Adubos e adubaçóes. São Paulo, Ed. Agronômica “CERES”, 1967. 606 p.

12. MIKKELSEN, D. S.; FREITAS, L. M. M. \& MCCLUNG, A. C. Efeitos da calagem e adubação na produção de algodão, milho e soja em três solos de campo cerrado. Matāo-SP, Instituto de Pesquisas IRI, 1963. 48 p. (Boletim n. ${ }^{\circ}$ 29) 
13. MOHR, W. A influência da acidez sobre a fertilidade dos solos. In: Congresso Nacional de Conservação de Solos, 1.․ Campinas-SP, 1960. 23 p.

14. REEVE, N. G. \& SUMNER, N. E. Effects of aluminum toxicity and phosphorus fixation on crop growth on oxisols in Natal. Soil Sci. Soc. Amer. Proc. 34:263 267, 1970.

15. SABINO, N. P. Efeitos da aplicaçāo de calcário, fósforo e potássio na qualidade da fibra do algodoeiro (Gossypium hirsutum L.) cultivado em latossolo roxo. Piracicaba, ESALQ, $1972.65 \mathrm{p}$. (Tese de doutoramento)

16. - LAZZARINI, J. F.; GRIDI-PAPP, I. L.; FUZATTO, M. G. \& GROSSI, J. M. M. Estudo de amostragens de capulhos em canteiros experimentais de algodăo. Bragantia $34: 163-169,1975$.

17. VERDADE, F. C.; GARGANTINI, H. \& MIRANDA, L. T. Uso e aplicação do calcário. Campinas, Instituto Agronômico, 1968. 63 p. (Campanha de calagem do solo)

18. WUTKE, A. C. P. Acidez. In: Elementos de Pedologia. São Paulo. Ed. USP. 1972. p. $149-168$.

19. - GRAGANTINI, H. \& GOMES, A. G. Avaliação das possibilidades de escórias de siderurgia como corretivos da acidez do solo. Bragantia 45:795-805, 1962. 